\title{
EVALUACIÓN DE LA EFICACIA BIOLÓGICA DE LOS FUNGICIDAS BAS 510 (BOSCALID) Y BAS 516 (BOSCALID + PYRACLOSTROBIN) PARA EL CONTROL DE Botrytis cinnerea EN EL CULTIVO DE TOMATE (Lycopersicum esculentum L.)
}

\author{
Bernardo Mora ${ }^{1}$
}

\section{RESUMEN}

Las enfermedades en el cultivo de tomate constituyen un factor limitante de la producción. El control de las diversas enfermedades causadas por hongos, se realiza por medio de fungicidas. El Moho Gris causado por el hongo Botrytis cinnerea es una enfermedad de gran relevancia en el cultivo, una vez que el sistema de plantación en el campo, se maneja con alguna estructura que favorece el desarrollo de la enfermedad. El objetivo del presente trabajo fue evaluar la eficacia biológica de los fungicidas, BAS 516 (Boscalid $252 \mathrm{~g} / \mathrm{kg}$ y Pyraclostrobin $128 \mathrm{~g} / \mathrm{kg}$ ); y BAS 510 (Boscalid $500 \mathrm{~g} / \mathrm{kg}$ ), en tres dosis cada uno. Se utilizaron dos testigos: uno, el programa de aplicaciones que utiliza el agricultor en la plantación y otro sin aplicación de fungicidas. El trabajo se realizó bajo un Diseño de Bloques Completos al Azar con cuatro repeticiones. Las aplicaciones se hicieron de forma semanal con bomba de motor y las evaluaciones de severidad de la enfermedad, también se llevaron a cabo cada semana. Los resultados de intensidad de la enfermedad, manifestaron una presencia homogénea y exclusiva del hongo en la plantación, lo cual facilitó realizar, una evaluación objetiva de la enfermedad en los diferentes tratamientos. Los niveles de severidad de infección y área bajo la curva de progreso de la enfermedad (ABCPE), demostraron diferencias significativas entre las diferentes dosis de los fungicidas. Los tratamientos BAS 510 y BAS 516 en las dosis de 1,5 I/ha y $1,25 \mathrm{l} / \mathrm{ha}$, respectivamente, fueron los que presentaron la menor severidad y la menor ABCPE. Las diferentes dosis de ambas moléculas aplicadas en el cultivo de tomate no tuvieron efecto fitotóxico, ni incompatibilidad con otras moléculas, por lo tanto se recomiendan como una nueva alternativa de control químico, para el manejo integrado del moho gris del tomate, causado por el hongo B. cinnerea.

Palabras clave: Tomate, fungicidas, eficacia biológica, control de Botrytis cinnerea.

\section{INTRODUCCIÓN}

El cultivo de tomate es la hortaliza de mayor importancia en área de siembra y consumo en el país. Es afectado por diversas plagas y enfermedades, que lo hacen una actividad de gran intensidad agronómica, por su exigente manejo. El hongo Botrytis cinnerea, causa las enfermedades más ampliamente distribuidas en los cultivos hortícolas, plantas ornamentales, frutales y algunas especies forestales (Aparicio et al. 1995, 1998); así como las enfermedades más comunes de las plantas cultivadas en los invernaderos (Villegas et al. 2000). Estas enfermedades se manifiestan principalmente en forma de tizones de inflorescencias y pudriciones del fruto, de tubérculos, bulbos y raíces, también como chancros o pudriciones del tallo, marchiteces de las plántulas, manchas foliares y como pudriciones (Domínguez 1993; Jarvis 1998). En condiciones de alta humedad relativa el hongo produce una capa fructífera conspicua de moho gris sobre los tejidos afectados (Gla-

1 Instituto Nacional de Innovación y Transferencia en Tecnología Agropecuaria (INTA). Costa Rica. 
ser y Guerrero 2000). Los cuerpos fructíferos del hongo o conidióforos constituyen uno de los problemas más graves de los cultivos de ambientes protegidos y en siembras a exposición solar, ya que las conidias se diseminan fácilmente y afectan diversos órganos de la plantas (Agrios 1996).

Algunas de las enfermedades más importantes ocasionadas por diversas especies del género Botrytis, incluyen al Moho Gris de la fresa, la pudrición por el moho gris de las hortalizas tales como la alcachofa, frijol, remolacha, col, zanahoria, pepino y berenjena; la pudrición del extremo de la punta de los plátanos, lechuga, pimiento, calabaza y tomate (Agrios 1996); la pudrición del cuello y tizón de la cebolla, la pudrición del extremo del cáliz de las manzanas, el tizón de las ramitas e inflorescencias del arándano, el tizón o moho gris de plantas ornamentales como la violeta africana, begonia, ciclamino, crisantemo, dalia, geranio, jacinto, lirio, rosa, tulipán (Sutton 1990; Sutton et al. 1997).

El patógeno Botrytis cinnerea pertenece a la clase de hongos imperfectos o Deuteromicetes, del orden Hyphomycetales (Agrios
1996). Se caracteriza por producir conidióforos largos y ramificados, cuyas células apicales y redondeadas poseen racimos de conidios de forma ovoide que son unicelulares, incoloros o de color gris los cuales libera bajo condiciones de clima húmedo y luego son diseminados por el viento. Produce esclerocios planos, irregulares, duros y de color negro. Algunas especies presentan la fase perfecta del hongo que coincide con Sclerotinia fuckeliana, en donde las ascósporas del hongo se forman sobre apotecios (Agrios 1996).

El patógeno inverna en el suelo en estado saprófito, en forma de esclerocios o de micelio, el cual se desarrolla sobre restos de plantas en proceso de descomposición (Aparicio et al. 1998). Se propaga por medio del agua de escorrentía y diversas prácticas culturales en restos vegetales, que puedan portar estructuras del hongo (Aparicio et al. 1995). No infecta las semillas de forma directa, pero puede propagarse con ellas como contaminante en la forma de esclerocios de tamaño similar o sobre restos de plantas. En presencia de un hospedero adecuado, se establece bajo condiciones propicias para su desarrollo,

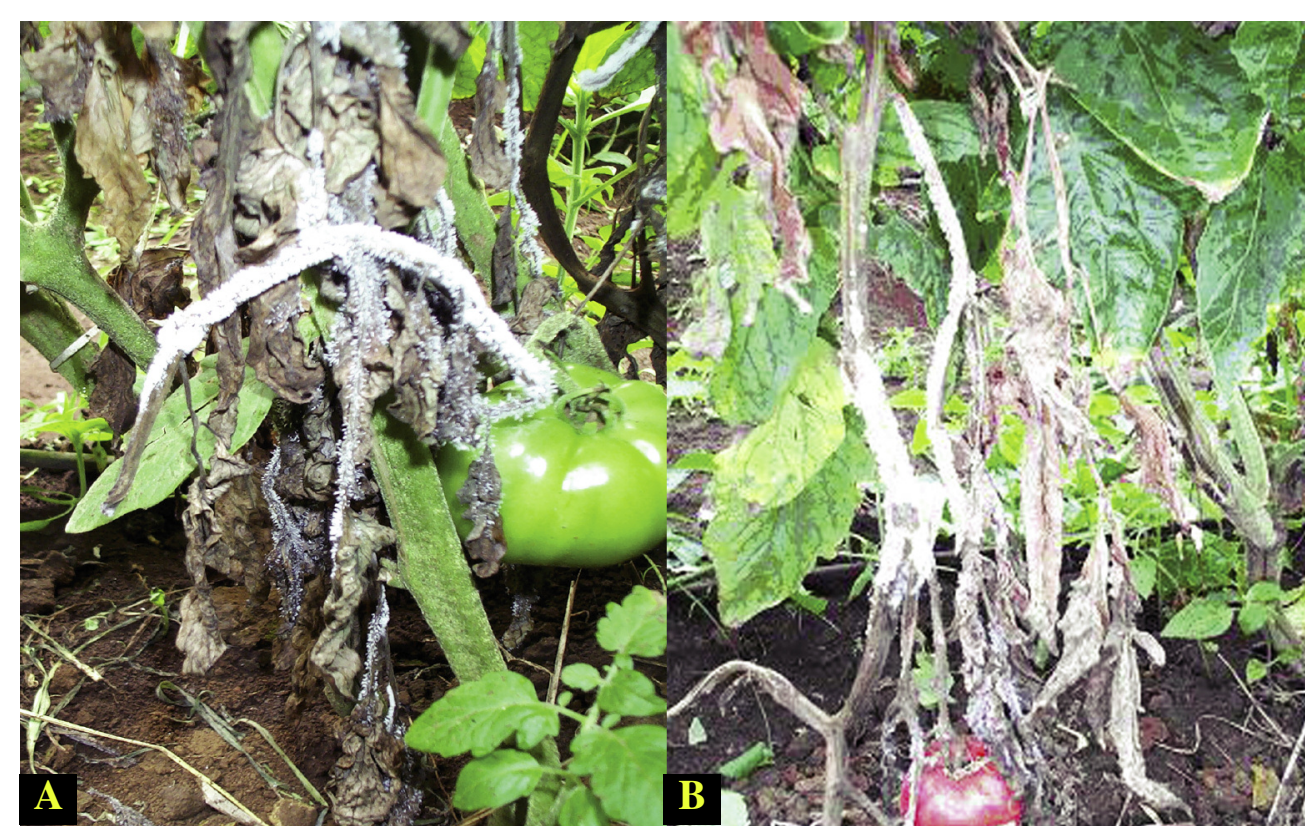

Figura 1. Síntomas del moho gris en tomate causado por $B$ cinnerea en las fases fenológicas de pre maduración del fruto $(A)$ y de cosecha $(B)$. 
como clima húmedo y moderadamente frío (18 a 23ㅇ C), donde los esclerocios germinan y producen infección, posteriormente las lesiones esporulan y liberan las esporas, para que se produzca un nuevo ciclo de infección (Blanchard 1996).

Los síntomas de la enfermedad son diversos en el cultivo de tomate, ya que el hongo ataca todos los órganos de la planta (Aparicio et al. 1995, 1998). Puede atacar tallos primarios, secundarios y terciarios, causando una marchitez sistémica y necrosamiento del tejido sobre el cual esporula. El efecto sistémico puede ser devastador si el hongo afecta el cuello del tallo principal de la planta, tal como se observa en las Figuras 1 y 2 . El hongo infecta las hojas causando lesiones necróticas y las flores produciendo la caída prematura posterior a su fertilización. También ocasiona la pudrición en los frutos. El síntoma particular en los frutos es denominado "mancha fantasma", se trata de ataques de $B$. cinnerea abortados, alrededor de un punto central muy pequeño y necrótico se observa un tenue anillo de cinco a $10 \mathrm{~mm}$ de diámetro, blanquecino sobre el fruto verde y maduro. La calidad interna del fruto no sufre ninguna variación, pero sí la presentación para el consumidor. El signo más común del patógeno es su espeso micelio blanco, que parasita los diferentes órganos de la planta y su excesiva esporulación

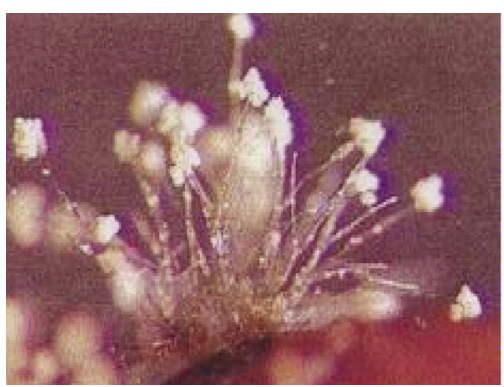

Conidióforos de Botrytis cinnerea

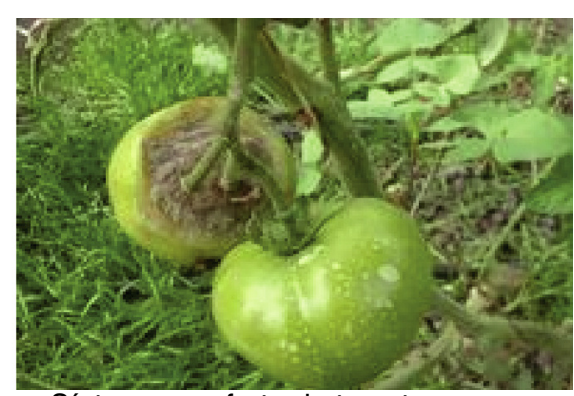

Síntomas en fruto de tomate

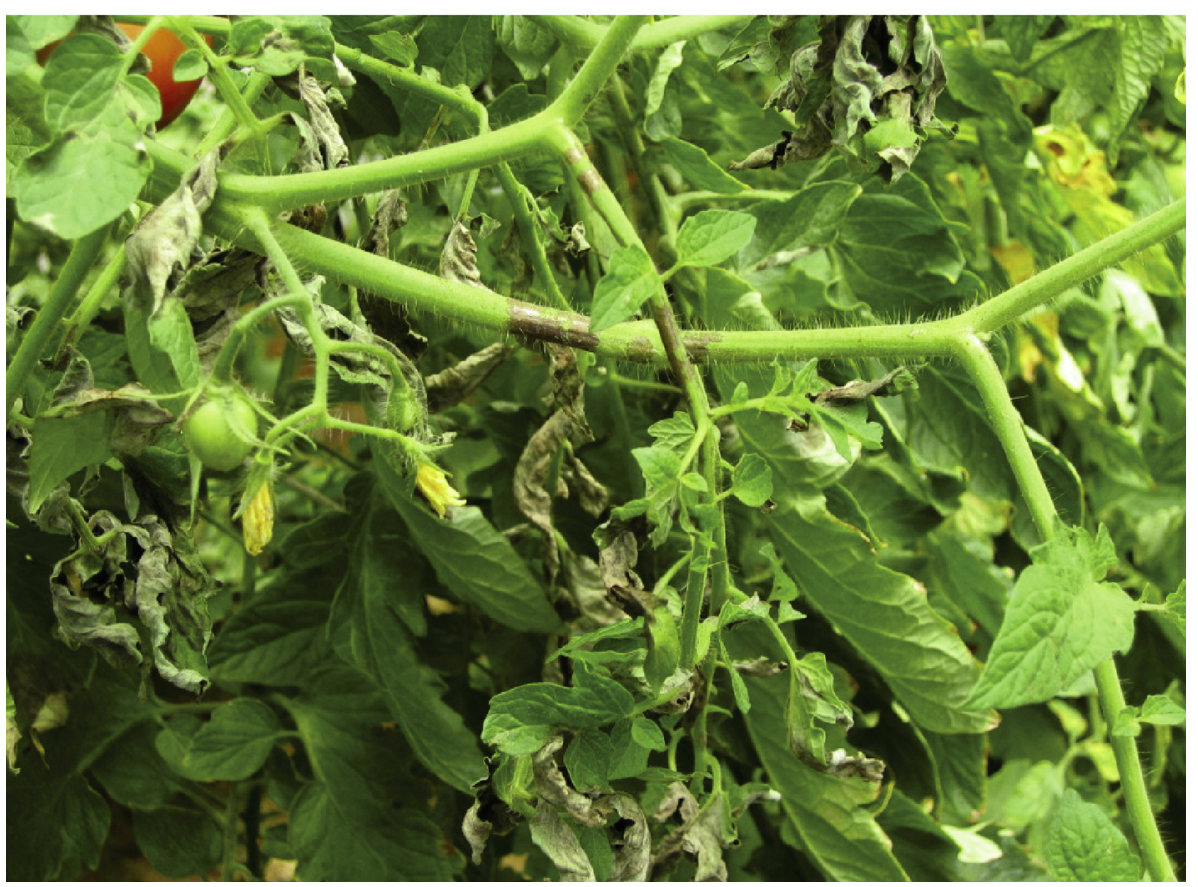

Síntomas latentes de moho gris en la hoja.

Figura 2. Conidióforos de Botrytis cinnerea, síntomas en frutos y síntomas latentes de poco desarrollo en hojas de tomate. 
en condiciones de alta humedad (Aparicio et al. 1998; Blanchard 1996; Domínguez 1993).

El objetivo del presente trabajo fue evaluar la eficacia biológica de los fungicidas BAS 516 (Boscalid + Pyraclostrobin) y BAS 510 (Boscalid) en tres dosis cada uno, para el control de Botrytis cinnerea en el cultivo de tomate.

\section{MATERIALES Y MÉTODOS}

El trabajo se realizó en la Ribera del Cantón de Belén, Heredia, a una altura de 1000 msnm. Los suelos son de origen volcánico de tipo inceptisol, con buen drenaje y aceptable fertilidad. La zona presenta dos épocas climáticas bien definidas; una lluviosa y de alta humedad relativa que va desde fines de abril a principios de diciembre; la otra se extiende de mediados de diciembre a fines de abril, la cual es de escasa precipitación y de menor humedad relativa. El sitio de prueba se caracteriza por recibir la influencia final de la corriente del Caribe que pasa a través del Paso de la Palma.

El trabajo se hizo durante los meses de junio y julio del año 2004. Las condiciones de clima durante el citado período se presentan en el Cuadro 1. El experimento se realizó en una plantación de tomate de primera cose- cha, con muy poca incidencia del hongo, pero con una distribución uniforme dentro de la plantación. El inóculo del patógeno con sus signos característicos, de micelio algodonoso y esporulación abundante, fue fácilmente detectable en el tercio medio de las plantas (Blanchard 1996). Las prácticas de cultivo en cuanto a manejo de la plantación y aplicación de agroquímicos, fueron las que emplean los agricultores del cultivo en la zona. En el experimento se utilizó la variedad de tomate cv. DeReuter 8108, sembrada a una densidad $1,80 \times 0,40$ metros para una población de 14.000 plantas por hectárea. La plantación fue protegida con un techo de plástico sostenido por varillas de acero de un cuarto de pulgada dobladas en forma de arco. Para evitar el amarre en cultivo se colocó una maya de nylon de $15 \mathrm{~cm} \mathrm{X} 15 \mathrm{~cm}$ de los $40 \mathrm{~cm}$, sobre el nivel del suelo hasta el arco que sostiene el techo de plástico, la maya estaba dispuesta en forma de uve (V) (Figura 3).

Los tratamientos que se evaluaron fueron: BAS 516 en las dosis de $0,8 \mathrm{~kg} / \mathrm{ha} 1,0 \mathrm{~kg} / \mathrm{ha}$; $1,2 \mathrm{~kg} / \mathrm{ha}$, y BAS 510 en las dosis de 1,0 $\mathrm{kg} / \mathrm{ha}$ y $1,2 \mathrm{~kg} / \mathrm{ha}$ y $1,4 \mathrm{~kg} / \mathrm{ha}$. Además se consideró como testigo comercial el programa de aplicaciones que utiliza el productor y un testigo absoluto sin aplicación de fungicida.

Los tratamientos se dispusieron en un diseño experimental de bloques completos al azar (BCA), con cuatro repeticiones. La

Cuadro 1. Datos promedios de precipitación, temperatura y humedad relativa, durante los meses de junio a julio, en períodos de 10 días. Aeropuerto Juan Santamaría*. Alajuela, 2004.

\begin{tabular}{|c|c|c|c|c|}
\hline \multirow{2}{*}{ Mes } & \multirow{2}{*}{$\begin{array}{l}\text { Precipitación } \\
\text { (mm) }\end{array}$} & \multicolumn{2}{|c|}{ Temperatura $\left({ }^{\circ} \mathbf{C}\right)$} & \multirow{2}{*}{$\begin{array}{l}\text { Humedad relativa máx. } \\
\qquad(\%)\end{array}$} \\
\hline & & Mínima & Máxima & \\
\hline Junio 1-10 & 29,1 & 18,9 & 23,9 & 72,2 \\
\hline Junio $11-20$ & 33,1 & 20,1 & 29,6 & 71,6 \\
\hline Junio $20-30$ & 20,6 & 19,8 & 29,9 & 69,9 \\
\hline Julio 1-10 & 71,9 & 18,7 & 28,5 & 70,4 \\
\hline Julio $11-20$ & 27,1 & 18,8 & 28,2 & 72,5 \\
\hline Julio 20-31 & 46,6 & 18,9 & 28,8 & 72,0 \\
\hline Tot / media & 228,4 & 19,2 & 28,1 & 71,4 \\
\hline
\end{tabular}

* Latitud norte $10^{\circ} 00^{\prime}$, Longitud oeste $84^{\circ} 12^{\prime}$ y altitud 932 msnm. 


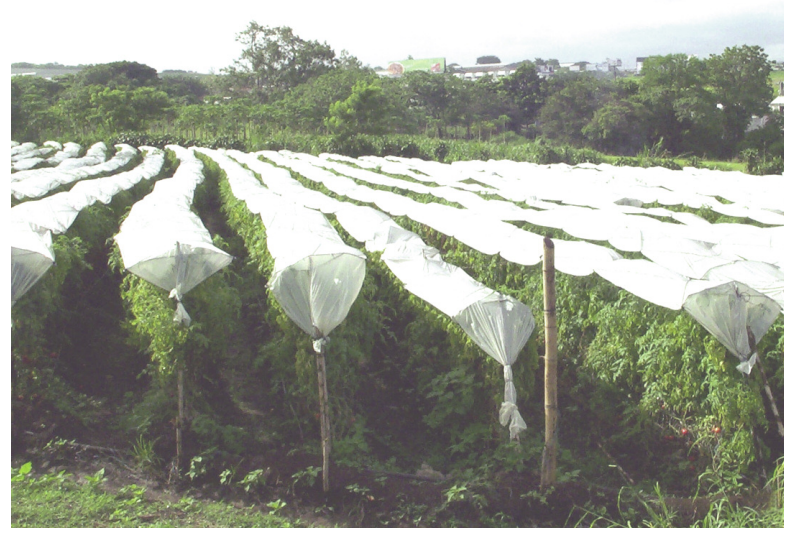

Figura 3. Sistema agronómico de manejo utilizado en la producción en el cultivo de tomate.

parcela experimental (sitio donde se realizó la aplicación de los fungicidas), consistió de tres surcos de seis metros de largo a una distancia entre plantas de 0,4 metros para un promedio de 48 plantas de tomate por parcela total. La parcela utilizada para realizar la evaluación de la enfermedad fue el surco central de los tres surcos de la parcela. La única enfermedad que estuvo presente fue $B$. cinnerea lo cual garantizó una evaluación muy objetiva de la severidad en el campo.

La aplicación de los fungicidas se realizó con un pulverizador motorizado de alta presión marca Eccho® SHP - 800, con tanque de 25 litros de capacidad. El equipo posee un volumen de descarga de 5,8 I por minuto y una presión (Mpa) 2,5 (máx.) (25kgf/cm² máx.). La boquilla utilizada es de tipo cono de dos cabezas, especial para plantaciones de tomate. El volumen de aplicación en promedio fue de 1000 litros por hectárea en planta productiva. El caldo fungicida se preparó un $50 \%$ solo y el otro $50 \%$ se hizo en mezcla con otros agroquímicos, como fertilizantes foliares, insecticidas, bactericidas y productos hormonales. Las aplicaciones no se hicieron al $100 \%$ en mezcla con otros agroquímicos, debido a que no se coincidió en la programación de aplicaciones del experimento con las aplicaciones que se realizaron en la siembra comercial. El número de aplicaciones de fungicidas fue de ocho y las evaluaciones de se- veridad de la enfermedad, fueron nueve durante los meses de junio y julio.

La intensidad de la enfermedad se evaluó por medio de la severidad de infección, definida como el porcentaje de tejido enfermo en el follaje afectado por el hongo. La severidad se determinó con una escala porcentual (Horsfall y Barrat 1945), la cual se basa en el principio físico de Weber y Fechner, que determina que el ojo humano discrimina diferencias de forma logarítmica. La escala en el rango de $0 \%$ al $50 \%$, determina los valores de: $0 \%-3 \% ; 3 \%-6 \% ; 6 \%-12 \% ; 12 \%-25 \%$ y $25 \%-50 \%$. Posteriormente de acuerdo con la experiencia del evaluador se hacen las interpolaciones necesarias. Por ejemplo entre 6 y $12 \%$, se interpola $9 \%$, y ente 6 y $9 \%$ se interpola $7,5 \%$, así de esta forma se logran rangos más cortos que permiten de forma objetiva, realizar una estimación de la severidad muy cercana a una media que representa la realidad. La escala también se utiliza con valores de $50 \%$ a $100 \%$ en la misma proporcionalidad que se explicó anteriormente, solo que en este caso es más utilizada para valores de incidencia y no de severidad.

El análisis de los resultados se efectuó por medio de un análisis de varianza (ANDEVA) y una prueba de separación de medias, por medio del SAS (Statistical Analysis System) de la Universidad de Carolina del Norte. También se obtuvo el Área Bajo la Curva de Progreso de la Enfermedad (ABCPE), para lo cual se utilizó la fórmula (Campbell y Madden 1990):

$A B C P E=\sum_{i}^{n-1}\left(y_{i}+y_{i+1} / 2\right)\left(t_{i+1}-t_{i}\right)$

ABCPE = porcentaje o proporción-días

$\mathrm{n}=$ Número de evaluaciones

$\mathrm{y}=$ Porcentaje $\mathrm{o}$ proporción de enfermedad en el tiempo 1

$\mathrm{y}=$ Porcentaje o proporción de la enfermedad en el tiempo 2 
Además se realizó el análisis de progreso de la enfermedad a través del tiempo, donde se determinaron los valores de tasa epidémica, de acuerdo al modelo logístico con la ecuación (Berger 1977, 1981):

$r=1 / \Delta t\left[\operatorname{logit} X_{2}-\operatorname{logit} X_{1}\right]$

$r=$ tasa de infección aparente o epidémica

$t=$ tiempo de una a otra evaluación:

$\mathrm{X}_{2}$ y $\mathrm{X}_{1}$ severidad de lecturas 1 y 2 respectivamente

logit $=\log _{e}\left[X_{n} / 1-X_{n}\right]$

\section{RESULTADOS Y DISCUSIÓN}

Las enfermedades producidas por hongos, virus y bacterias, encuentran en el cultivo de tomate un excelente sustrato para su reproducción, razón por la cual los programas de mejoramiento genético de diversas compañías transnacionales, generan germoplasma de tomate con resistencia a unos cuantos patógenos, pero no a su totalidad en condiciones tropicales.

En el cultivo de tomate el control químico constituye la principal estrategia de manejo de las enfermedades (Latorre et al. 2000; Villegas et al. 2000; Rioja et al. 2000). Por esta razón, es que diferentes compañías transnacionales evalúan de forma periódica, diversas moléculas (Dave et al. 2001; Knight et al.1997), programas de atomización, para los diferentes organismos causantes de plagas y enfermedades, que son limitantes en la producción del cultivo.

Es importante mencionar, que no todas las enfermedades producidas por hongos, conllevan el mismo tipo de control químico. El control de una roya (Uredinales) difiere sustancialmente al de un hongo del grupo de los Peronosporales o al de un hongo imperfecto (Agrios 1996). El Moho Gris del tomate tiene características muy especiales en su epidemiología, por la amplia diversidad genética de hospederos que afecta el hongo, su capacidad de sobrevivencia en épocas adversas por medio de esclerocios y su capacidad de producir el estado sexual (Sutton 1990). La evaluación y selección de fungicidas para este hongo es muy importante, ya que el grupo de fungicidas para el control de Botrytis spp, es muy restringido, debido a que el patógeno puede de forma rápida desarrollar resistencia a las diversas moléculas (Sutton 1997; Valli y Moorman 1992). La resistencia a benzimidazoles y dicarboximidas como iprodione, procymidone y vinclozolin ha sido reportada en el cultivo de la vid, fresas y cultivos de invernadero (Valli y Moorman 1992). Además, se reporta resistencia cruzada entre razas con resistencia a benzimidazoles y dicarboximidas, lo cual dificulta el manejo de la enfermedad por medio de fungicidas (Valli y Moorman 1992; Dave et al. 2001; Knight et al. 1997).

La evaluación de la severidad de la enfermedad en el cultivo por medio de una escala porcentual (Horsfall y Barrat 1945), constituye una buena metodología, ya que permite realizar una valoración objetiva del nivel de daño. La escala permite valoraciones consistentes en el rango de $0 \%$ al $50 \%$ (Campbell y Madden 1990). Infecciones arriba del 50\% significan epidemias muy agresivas generadas por diversos factores como germoplasma muy susceptible, ausencia de control químico o inadecuadas prácticas culturales (Campbell y Madden 1990; Van der Plank 1963). En algunos casos las condiciones de clima son tan favorables para el patógeno, que puede sobrepasar el umbral de resistencia genética, control químico y con gran facilidad la práctica cultural (Robinson 1976).

El Cuadro 2, presenta los diferentes tratamientos y dosis con los datos de severidad, área bajo la curva de progreso de la enfermedad (ABCPE). Las tres dosis de BAS 516, para severidad y $A B C P E$ son estadísticamente similares y lo mismo se manifiesta con las tres dosis de BAS 510. Ambos testigos son estadísticamente diferentes entre sí y diferentes de los promedios de severidad y ABCPE de los demás tratamientos, a excepción de la menor dosis del fungicida BAS 510, que es estadísticamente igual al Programa del Agricultor. 
Cuadro 2. Efecto de varias dosis de fungicidas en la severidad, área bajo la curva de progreso de la enfermedad (ABCPE) y tasa epidémica $r_{L}$, causada por el hongo Botrytis cinnerea en el cultivo de tomate. Belén, Heredia 2004.

\begin{tabular}{|c|c|c|c|c|c|c|}
\hline $\mathbf{N}^{\circ}$ & Tratamiento & $\begin{array}{c}\text { Dosis } \\
\mathrm{kg} / 200 \text { I }\end{array}$ & $\begin{array}{l}\text { Dosis } \\
\mathrm{kg} / \mathrm{ha}\end{array}$ & Severidad* & $\mathrm{ABCPE}^{*}$ & $\begin{array}{c}\text { Tasa } \\
\text { epidémica }\end{array}$ \\
\hline 1 & BAS 516 Bellis@ 37 WG & 0,16 & 0,8 & $23,45 \mathrm{~cd}$ & 600,6 & 0,0669 \\
\hline 2 & BAS 516 Bellis $₫ 37$ WG & 0,20 & 1,0 & $22,70 \mathrm{~cd}$ & 586,8 & 0,0620 \\
\hline 3 & BAS 516 Bellis® 37 WG & 0,25 & 1,2 & $20,90 \quad d$ & $545,2 \quad c$ & 0,0571 \\
\hline 4 & BAS 51050 WG & 0,20 & 1,0 & $29,40 \mathrm{bc}$ & $747,3 \mathrm{bc}$ & 0,0679 \\
\hline 5 & BAS 51050 WG & 0,25 & 1,2 & $25,00 \mathrm{~cd}$ & $644,7 \quad c$ & 0,0630 \\
\hline 6 & BAS 51050 WG & 0,30 & 1,4 & $22,30 \mathrm{~cd}$ & $579,2 \quad c$ & 0,0606 \\
\hline 7 & Programa finca & - & - & $33,70 \mathrm{~b}$ & 858,1 b & 0,0681 \\
\hline 8 & Testigo Absoluto & - & - & $48,70 \mathrm{a}$ & $1221,4 \mathrm{a}$ & 0,0818 \\
\hline
\end{tabular}

* Medias con igual letra, no son estadísticamente diferentes, de acuerdo a la prueba de Rangos Múltiples de Duncan.

La Figura 4, muestra que el progreso de la enfermedad tuvo una tendencia de distribución normal, que se ajusta a un modelo de tipo Logístico o de Gompertz (Berger 1981; Van der Plank 1963). En todos los tratamientos, la enfermedad inicia con una cantidad de inóculo inicial $Y_{0}$, muy bajo, tal como se determinó en la primera evaluación de la severidad. Posteriormente comienza una fase de desarrollo exponencial de la enfermedad en la primera semana de evaluación de la severidad (Berger 1981; Van der Plank 1963, 1982). A partir de la segunda semana se pre- senta una fase logarítmica bastante acelerada, que comprende el período de mediados de junio a fines de julio. Este incremento acelerado se nota principalmente en el tratamiento de Testigo Absoluto, con una tasa epidémica de 0,0818 unidades día, calculada en un período de 59 días, si se compara con la tasa epidémica del tratamiento de BAS 516 1,2 $\mathrm{kg} / \mathrm{ha}$ de 0,0571 . La tasa epidémica en el tratamiento del programa finca fue de 0,0681. La fase terminal de la enfermedad, ocurre a principios de agosto por dos razones: una debido a que se acentúa el período de canícula, don-

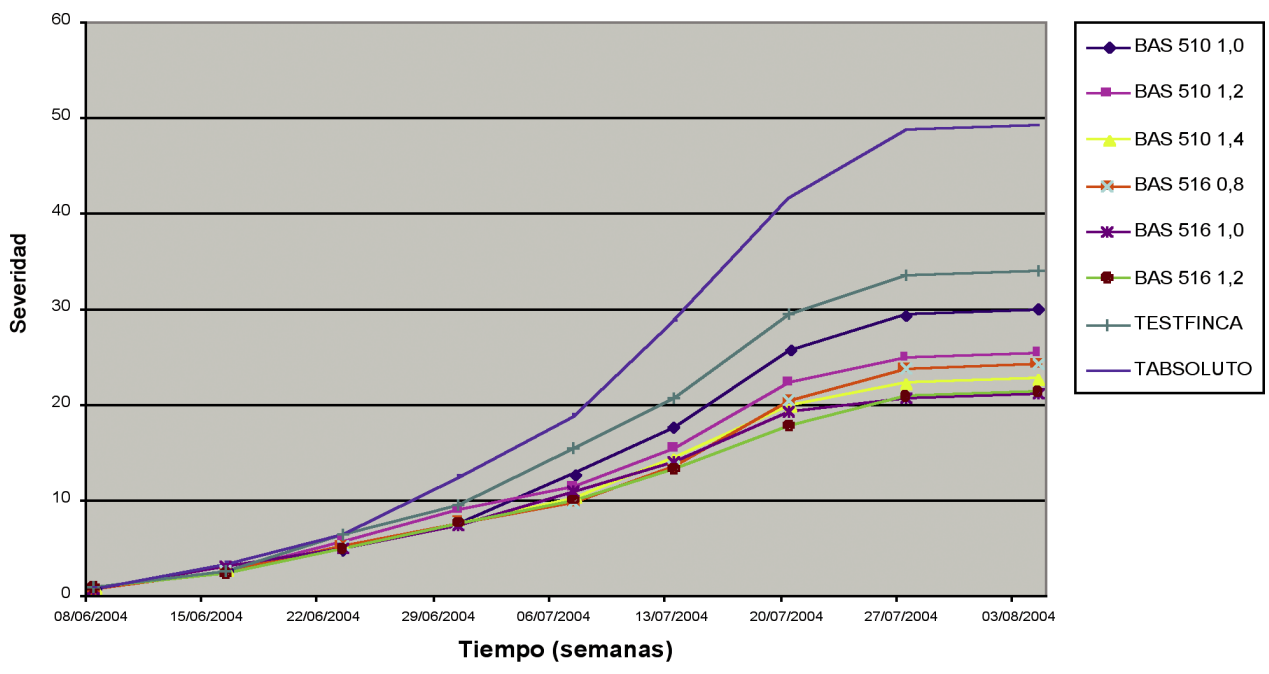

Figura 4. Evaluación de la eficacia biológica de fungicidas, para el control de Botrytis cinnerea en el cultivo de tomate. Belén, Heredia, 2004. 
de se presentan condiciones muy desfavorables para el desarrollo del hongo. La segunda razón es que el cultivo entra en la etapa de senescencia y declino de la cosecha. No obstante estas razones, cabe mencionar que todas aquellas parcelas que recibieron el tratamiento fungicida, tuvieron una etapa de senescencia de mayor verdor, como consecuencia de una prolongación de su vida útil, que favoreció un mayor rendimiento del cultivo. El concepto anterior podría ser importante en períodos donde se mantenga un buen precio del tomate en el mercado.

Los datos de clima que se presentan en el Cuadro 1, muestran que las condiciones durante los meses de junio y julio fueron sumamente favorables para el desarrollo del cultivo y por ende para la producción de tomate. El total acumulado de la precipitación fue de $228,4 \mathrm{~mm}$, lo cual apenas podría considerarse suficiente para las necesidades hídricas del cultivo. Una humedad relativa promedio del $71,4 \%$, puede considerarse intermedia para llenar las necesidades de algunos patógenos causantes de enfermedades. Los anteriores datos de clima indican que Botrytis cinnerea es un hongo que no necesita condiciones especiales de clima para causar severos daños. El rango de temperatura que se presenta en el cuadro citado, poca precipitación y humedad relativa intermedia de $65 \%$ a $75 \%$, serían condiciones favorables para causar severas epidemias. Debe recordarse que este hongo es el causante de diversas enfermedades en los invernaderos $y$

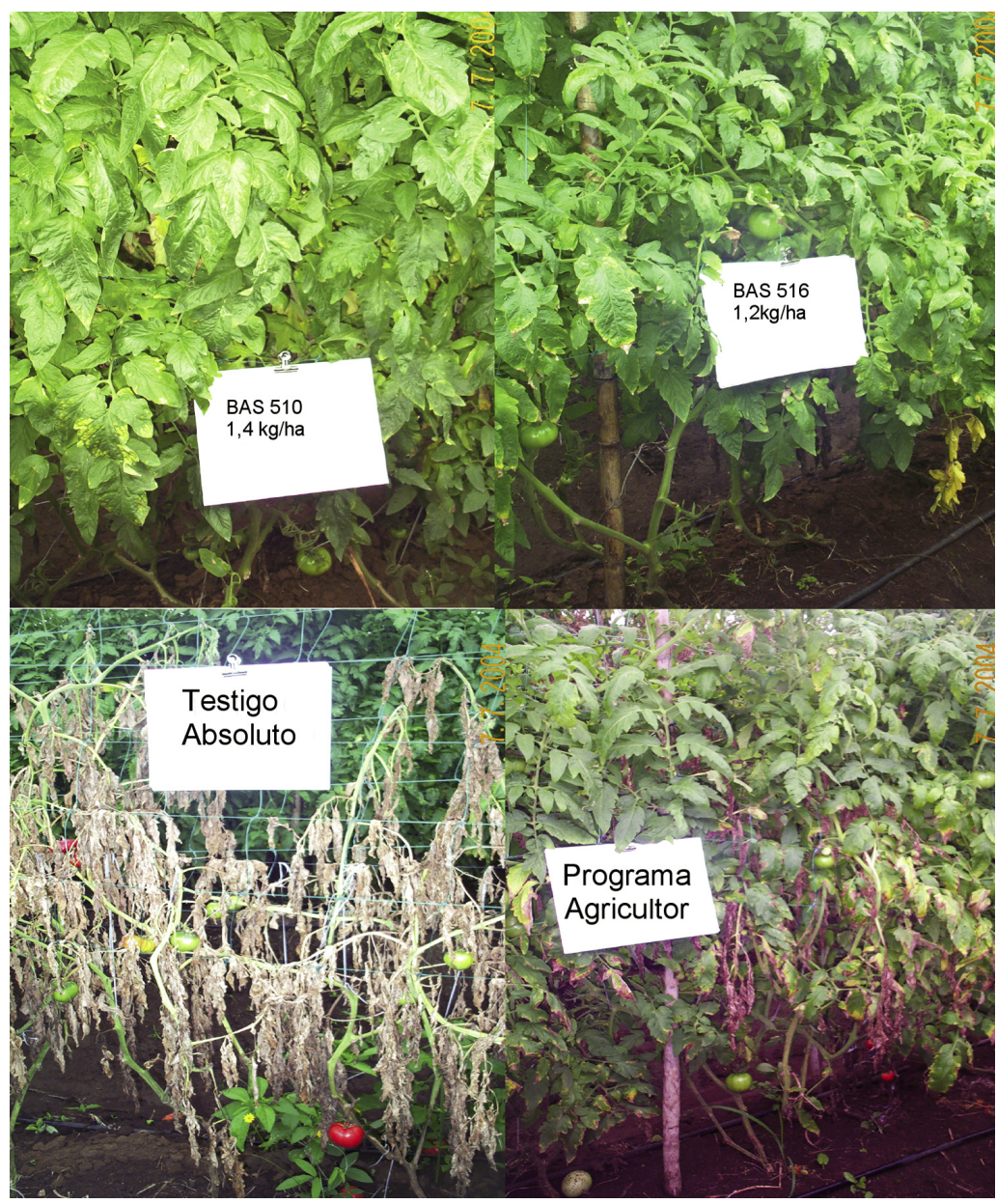

Figura 5. Comparación de los fungicidas probados con el tratamiento de testigo absoluto y el programa de atomizaciones que utiliza el agricultor. Belén, Heredia, 2004. 
generalmente son condiciones muy favorables para el desarrollo y producción de los diferentes cultivos. La actual producción del cultivo de tomate, conlleva la utilización de alguna estructura que lo proteja principalmente de la excesiva precipitación en algunos meses del año. Esta estructura de techos en la parte superior del dosel de la planta, también facilita el desarrollo del moho gris, razón por la cual es necesario desarrollar una buena estrategia para el manejo de esta enfermedad.

Las fotografías que se presentan en la Figura 5 muestran el estado final de las plantas según los tratamientos aplicados, cuando se hizo la última evaluación de la severidad de infección. Cabe aclarar que las fotografías muestran el potencial de cada uno de los tratamientos, ya que no todos los testigos tuvieron una pérdida total como se aprecia en la foto, ni todos los otros tratamientos fueron tan sanos como los de la foto de la Figura 5. No obstante, la variación de los tratamientos en las cuatro repeticiones para las variables de Severidad y ABCPE fueron de $17 \%$ y 18 $\%$, respectivamente, lo cual es un dato muy aceptable, sí se considera la variación de las epidemias en condiciones de campo.

El resultado de los datos anteriores permite observar que el fungicida BAS 516 , es eficiente para el control de Botrytis cinnerea en el cultivo de tomate, en las tres dosis estudiadas. También, el fungicida experimental BAS 510 presentó eficacia biológica para el control del hongo en las dosis analizadas. Los dos fungicidas fueron utilizados, en la mitad de las aplicaciones solas y la otra mitad de los fungicidas se acompañó con otros agroquímicos, que se utilizan en el cultivo de tomate. Esta diferenciación no fue a propósito, sino que las aplicaciones de los fungicidas se programaron de forma semanal y cuando coincidieron las aplicaciones del experimento y los de la plantación, las aplicaciones de productos se hicieron de forma conjunta.

\section{CONCLUSIONES Y RECOMENDACIONES}

1. Los dos fungicidas tuvieron eficacia biológica para el hongo Botrytis cinnerea.

2. Los fungicidas no fueron fitotóxicos al tomate solos, ni en mezclas con otros agroquímicos.

3. Es recomendable utilizar los fungicidas solos o en mezcla con otros productos, ya que esto, además de medir la eficacia biológica del producto contra el hongo, permite determinar las interacciones con otros plaguicidas y sus posibles toxicidades.

4. Se recomienda la validación de los fungicidas en plantaciones comerciales de tomate.

5. Se recomienda concentrar las aplicaciones de fungicida en la etapa productiva del cultivo, con el objetivo de alargar el período de cosecha, ya que el hongo se especializa en atacar diversos órganos de la planta, en especial el fruto.

6. Se recomienda un número de cuatro a seis aplicaciones, durante el ciclo del cultivo, ya que el hongo puede adquirir una rápida resistencia a las moléculas del grupo de los benzimidazoles y carboximidas (Latorre et al. 2000).

7. Debe considerarse una buena estrategia de mercadotecnia de la compañía y un uso adecuado de parte de los agricultores, para prolongar la vida útil de ambos fungicidas en el mercado nacional.

\section{AGRADECIMIENTO}

Al productor de tomate, Dauve Rojas Jiménez, por su desinteresada colaboración en 
la ejecución del presente trabajo. A la Compañía BASF por el suministro de los fungicidas que fueron evaluados.

\section{LITERATURA CITADA}

Agrios, G.N. 1996. Fitopatología. Ed. Limusa, S.A. México. 838 p.

Aparicio, V.; Belda J.E.; Casado, E; García, M.; Gómez, V.; Lastres, J.; Mirasol, E.; Roldán, E.; Sáez, E.; Sánchez, A.; Torres, M. 1998. Plagas y enfermedades en cultivos hortícolas de la provincia de Almería: control racional. Consejería de Agricultura y Pesca. España. Junta de Andalucía. Sevilla: 356 p.

Aparicio, V.; Rodríguez, M.D.; Gómez, V.; Sáez, E.; Belda J.E.; Casado, E.; Lastres, J. 1995. Plagas y enfermedades del tomate en la provincia de Almería: control racional. Consejería de Agricultura y Pesca. Junta de Andalucía. España. Sevilla: 182 p.

1995. Plagas y enfermedades de los principales cultivos hortícolas de la provincia de Almería: control racional. Consejería de Agricultura y Pesca. Junta de Andalucía. España. Sevilla: 260 p.

Dave W.; Bartlett, D. W.; Clough, J.M.; Godfrey, C. A.; Godwin, J. R.; Hall, A, A.; Heaney, S. P.; Maund, S. J. 2001. Understanding strobilurin fungicides. Pesticide Outlook August.143 p.

Berger, R. B. 1977. Application of epidemiological principles to achieve plant disease control. Annu. Rev. Of Phytopathology. 15: 165-183.

Berger, R. B. 1981. Comparison of the Gompertz and Logistic equation to describe plant disease progress. Phytopathology 71: 716-719.

Blanchard, D. 1996. Enfermedades del tomate. Ed. Mundi-Prensa. Madrid. España 212 p.

Campbell, C. L.; Madden, L.V. 1990. Introduction to Plant Disease Epidemiology. A. Willey Intercience Publication. 532 p.

Domínguez, F. 1993. Plagas y enfermedades de las plantas cultivadas. Mundi-Prensa. Madrid. España. $821 \mathrm{p}$.
Glaser, G. C.; Guerrero, C. J. 2000. Control de Botrytis cinnerea Pers. en Tulipán (Tulipia spp.) cv. Pandión. Fac. Ciencias Agropecuarias y Forestales. Universidad de la Frontera. Temuco, Chile. sp.

Jarvis, W.R. 1998. Control de enfermedades en cultivos de invernadero. Mundi-Prensa. Madrid. España. 334 p.

Horsfall, J.G.; Barrat, R. W., 1945. An improved grading system for measuring plant disease. Phytopathology. 35: 655. (abstr.)

Knight S.C.; Anthony, V. M.; Brady, A M.; Greenland, A. J.; Heaney, S. P.; Murray, D. C.; Powell, K. A.; Schulz, M. A.; Spinks, C.A.; Worthington, P. A.; Youle, D. 1997. On the development of fungicides. Annual Review Phytopathology 35:349-72

Latorre, B; Spadaro, I.; Rioja, M. E.; Lillo, C. 2000. Rápido cambio en la sensibilidad de Botrytis cinerea a fungicidas anilinopirimidinas. Facultad de Agronomía e Ingeniería Forestal, Pontificia Universidad Católica de Chile, Santiago, Chile. X Congreso Nacional de Fitopatología, Resúmenes. Presentaciones orales. sp.

Rioja, M. E.; Finlay, R.G.; Latorre, B. 2000. Variabilidad en la respuesta a la temperatura de incubación observada en aislamientos de Botrytis cinerea, Facultad de Agronomía e Ingeniería Forestal, Pontificia Universidad Católica de Chile, Santiago, Chile, Resúmenes, Presentaciones orales. sp.

Robinson, R. 1976. Plant Pathology systems. Springer - Verlag. $184 \mathrm{p}$.

Sutton, J. C. 1990. Epidemiology and management of Botrytis leaf blight of onion and gray mold of strawberry: a comparative analysis. Can. J. Plant Pathol. 12: 100-110.

Sutton, J. C; Li Wei-De; Peng Gang; Yu Hai; Zhang Pinggao; Valdebenito-Sanhueza R. M. 1997. Gliocladium Roseum a versalile adversary of Botrytis cinerea in crops. Plant Disease 81(4): 316-328.

Valli, R. J.; Moorman, G. W. 1992. Influence of selected fungicide regimes on frequency of dicarboximides-resistant and dicarboximidesensitive strain of Botrytis cinerea. Plant. Dis. 76: 919-924. 
Van der Plank. J. E. 1963. Plant disease: epidemics and control. Academic. New York. 344 p.

1982. Host pathogens interaction in plant disease academic. New York. 192 p.

Villegas, I; Apablaza, G. San Martín, R. 2000. Efectos de control de QL-1000 y QL-ultra, productos del quillay sobre moho gris del tomate (Botrytis cinerea) en producción de invernadero. Pontificia Universidad Católica de Chile, Facultad de Agronomía e Ingeniería Forestal. Escuela de Ingeniería Química y Bioprocesos X Congreso Nacional de Fitopatología, Resúmenes, Presentaciones orales. sp. 